\title{
Studies of Phase Diagram of a Liquid Crystal with 4-[2-(3-Fluorophenyl)ethyl]biphenyl Core of Molecules
}

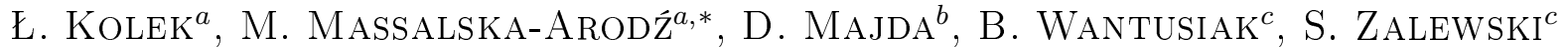 \\ AND P. KuLA ${ }^{d}$ \\ ${ }^{a}$ Institute of Nuclear Physics, Polish Academy of Sciences, E. Radzikowskiego 152, 31-342 Kraków, Poland \\ ${ }^{b}$ Faculty of Chemistry, Jagiellonian University, R. Ingardena 3, 30-060 Kraków, Poland \\ ${ }^{c}$ Institute of Chemistry, Siedlce University of Natural Sciences and Humanities \\ 3-go Maja 54, 08-110 Siedlce, Poland \\ ${ }^{d}$ Institute of Chemistry, Military University of Technology, S. Kaliskiego 2, 00-908 Warszawa, Poland

\begin{abstract}
Basing on the results of differential scanning calorimetry and transmitted light intensity methods and texture observations in the temperature range from $-50{ }^{\circ} \mathrm{C}$ to $90^{\circ} \mathrm{C}$ phase diagram of 1 -[3-fluoro-4-(1-methylheptyloxycarbonyl)phenyl]-2-[4'-(2,2,3,3,4,4,4-heptafluorobutoxybutoxy)biphenyl-4-yl]ethane was established. Monotropic system of thermodynamic phases was found. On cooling the isotropic phase transforms at $85^{\circ} \mathrm{C}$ to ferroelectric $\mathrm{SmC}^{*}$ phase and further two liquid crystalline phases, antiferroelectric $\mathrm{SmC}_{\mathrm{A}}^{*}$ and $\mathrm{SmI}$, and a metastable crystal Cr2 reveal. During heating exothermic anomaly in the wide temperature range was observed and ascribed to evolution of $\mathrm{Cr} 2$ to the stable crystal $\mathrm{Cr} 1$. On further heating both $\mathrm{SmC}_{\mathrm{A}}^{*}$ and $\mathrm{SmC}^{*}$ phases were observed. Thermodynamic parameters were calculated for all phase transitions. During rapid cooling $(10 \mathrm{~K} / \mathrm{min})$ vitrification of metastable $\mathrm{Cr} 2$ crystal at $T_{\mathrm{g}}=-115^{\circ} \mathrm{C}$ was registered.
\end{abstract}

PACS: 64.70.M-, 62.20.Jk

\section{Introduction}

Substances with elongated organic molecules often form various liquid crystalline mesophases, i.e. liquid phases having long range order of some degrees of freedom, which results in anisotropy of their physical properties [1]. Since 1976 liquid crystalline phases of ferroelectric ordering of molecules are known [2] and in 1989 first substance with antiferroelectric liquid crystalline phase was synthesized [3]. Many compounds reveal both phases during changes of temperature or pressure [4]. Non-zero component of molecular electric moment perpendicular to the long axis of molecules is a factor necessary for ferroelectric ordering. Due to dipolar interactions helical structures are formed with a helical pitch of $100 \mathrm{~nm}$. Physical properties of such type of compounds are investigated intensively due to the possible applications in optoelectronics. There is a great interest in synthesis of substances having wide temperature range of ferroelectric phase in the vicinity of room temperature, appropriate viscosity and spontaneous electric polarization, and short time of switching of the polarization vector by small electric voltage.

\footnotetext{
* corresponding author
}

In the paper thermal behaviour of elongated molecules of 1-[3-fluoro-4-(1-methylheptyloxycarbonyl)phenyl]-2-[4'-(2,2,3,3,4,4,4-heptafluorobutoxybutoxy) biphenyl-4yl]ethane having chiral center in the alkyl chain and dipolar moment perpendicular to the long axes due to several dipole molecular groups (-COO-, $-\mathrm{CF}$ and -COC-) was studied.

Molecular structure of the substance is presented in Fig. 1. For identification of phases and establishing of a phase diagram three complementary experimental methods were used: differential scanning calorimetry (DSC), transmitted light intensity (TLI) and texture observations by polarizing microscope (POM). Preliminary DSC thermogram [5] obtained above room temperature showed the presence of the ferroelectric smectic $\mathrm{SmC}^{*}$ and the antiferroelectric smectic $\mathrm{SmC}_{\mathrm{A}}^{*}$ phases.

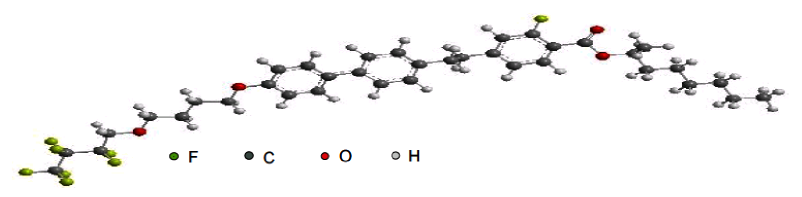

Fig. 1. Molecular structure of 1-[3-fluoro-4-(1-methylheptyloxycarbonyl)phenyl]-2-[4'-(2,2,3,3,4,4,4-heptafluorobutoxybutoxy)biphenyl-4-yl]ethane. 


\section{Experimental}

The compound was synthesized at the Department of Chemistry, Military University of Technology, Warsaw. Detailed DSC measurements of the temperature changes of heat flow to the sample were performed using $822^{e}$ Mettler Toledo equipment. The sample was placed in an aluminum vessel of $40 \mu \mathrm{l}$ capacity. Experiment consisted of several cycles of heating and cooling the sample in the temperature range from $-150{ }^{\circ} \mathrm{C}$ to $90^{\circ} \mathrm{C}$ with the rate of temperature change of $2,5,10$ and $20 \mathrm{~K} / \mathrm{min}$. Measurements of transmitted light intensity and texture observations were performed using polarizing microscope in the temperature range from $-30^{\circ} \mathrm{C}$ to $100^{\circ} \mathrm{C}$ on cooling and heating with the rate of temperature change of $1 \mathrm{~K} / \mathrm{min}$ and $5 \mathrm{~K} / \mathrm{min}$ by TLI and $1 \mathrm{~K} / \mathrm{min}$ by POM. In TLI method eyepiece was replaced in the microscope by a high sensitivity photodetector which converted the light intensity to voltage signal.

\section{Results and discussion}

In Fig. 2 the textures of four phases observed by polarizing microscope during cooling the isotropic phase of 1-[3-fluoro-4-(1-methylheptyloxycarbonyl)phenyl]-2-[4'-(2,2,3,3,4,4,4-heptafluorobutoxybutoxy)biphenyl-4 -yl]ethane are shown. One can see a succession of textures observed for $\mathrm{SmC}^{*}, \mathrm{SmC}_{\mathrm{A}}^{*}$, for a newly found liquid crystalline phase and finally for a crystal. New phase reveals a fan texture so we assume that it is the smectic I* phase $\left(\mathrm{SmI}^{*}\right)$ as for the other substances of similar properties [6].

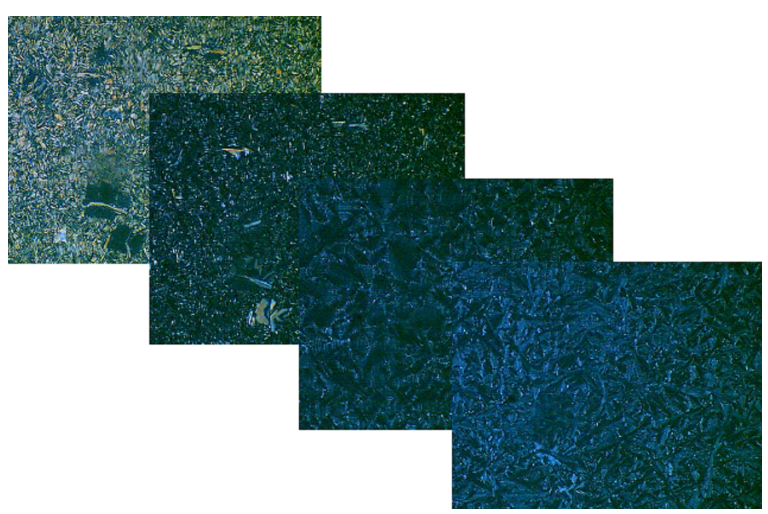

Fig. 2. Textures observed in the eyepiece of the polarizing microscope on cooling the sample with the rate of $1 \mathrm{~K} / \mathrm{min}$. From the upper left corner successively: $\mathrm{SmC}^{*}, \mathrm{SmC}_{\mathrm{A}}, \mathrm{SmI}^{*}$, and crystalline phase.

In the next step the phase sequence was checked down to $-50{ }^{\circ} \mathrm{C}$ using DSC and down to $-30{ }^{\circ} \mathrm{C}$ by TLI measurements. In both methods a sample was first heated to the isotropic phase.

In Fig. 3 the DSC thermogram obtained during cooling and heating the sample with the rate of $2 \mathrm{~K} / \mathrm{min}$ is shown. One can see that in the heat flow vs. temperature curves the sequence of the thermal anomalies depends on the direction of the temperature change. A low-energy transition from $\mathrm{SmC}_{\mathrm{A}}^{*}$ phase to the $\mathrm{SmI}$ phase and then its crystallization are visible on cooling only.

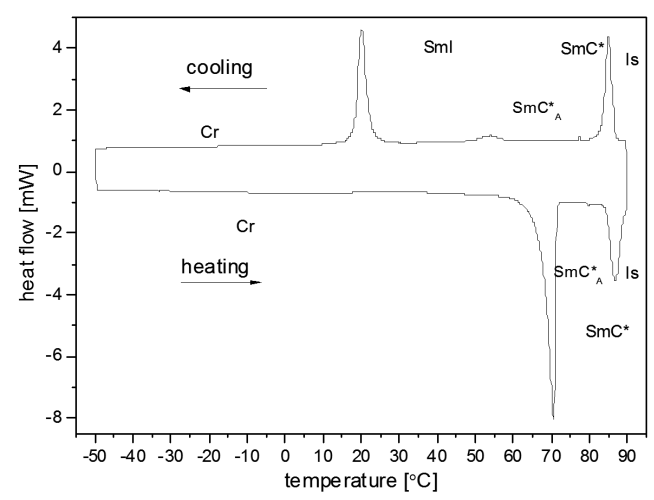

Fig. 3. DSC thermogram in the temperature range from $-50{ }^{\circ} \mathrm{C}$ to $90^{\circ} \mathrm{C}$ for heating and cooling with a rate of $2 \mathrm{~K} / \mathrm{min}$.

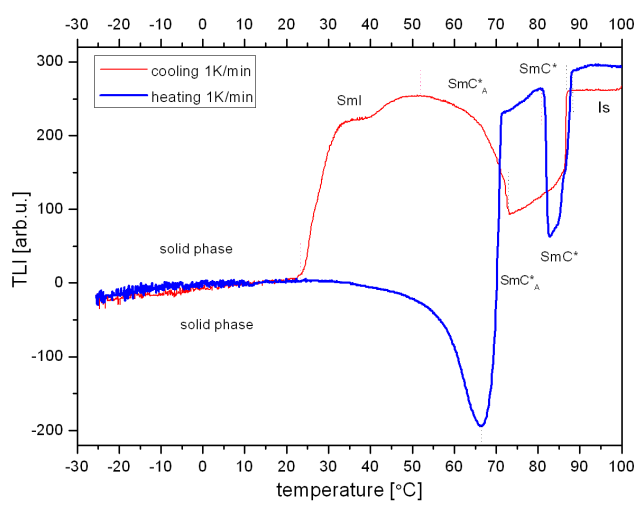

Fig. 4. Transmitted light intensity as a function of temperature in the range from $-25^{\circ} \mathrm{C}$ to $100{ }^{\circ} \mathrm{C}$ for cooling and heating with the $1 \mathrm{~K} / \mathrm{min}$ rate of temperature changes.

Figure 4 presents the intensity of transmitted light as a function of temperature. TLI plot analysis allows to confirm the monotropic system of phase transitions obtained by DSC method. Values of phase transition temperatures are slightly different in each method, due to the slower rate of temperature changes in the TLI as compared to the DSC measurements. Difference in intensities detected at the same $\mathrm{SmC}^{*}$ phase on cooling and on heating is caused mainly by the fact that arrangement of the molecules in the sample depends on the direction of temperature changes.

Further, DSC measurements were repeated in order to see in more detail thermal behavior of the sample at different conditions of experiment. The measurements were done for the same sample as before. It was stored at room temperature for about two weeks before starting 
the first cycle: temperature was decreased with the rate of $10 \mathrm{~K} / \mathrm{min}$ down to $-50{ }^{\circ} \mathrm{C}$ and then increased at the same rate to $90^{\circ} \mathrm{C}$. The next cycles were performed by cooling and heating the sample with different rates of temperature changes. In Fig. 5 the DSC thermograms for $2,5,10$, and $20 \mathrm{~K} / \mathrm{min}$ rates of heating and cooling are presented. The phase transition temperatures observed in the DSC method are summarized in Table I.

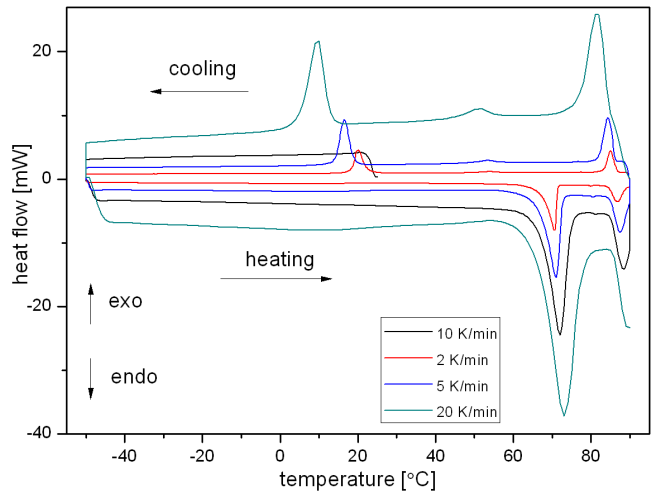

Fig. 5. DSC thermogram obtained on cooling and heating with the rate of $2,5,10$, and $20 \mathrm{~K} / \mathrm{min}$.

One can see that during the first cycle $(10 \mathrm{~K} / \mathrm{min})$ on cooling from room temperature no thermal anomaly appears and on heating the first anomaly appears at approximately $72^{\circ} \mathrm{C}$. Such thermogram was not obtained in subsequent cycles. Contrary to that in each of them during cooling not only high-energy peak associated with the transition of $\mathrm{SmI}^{*}$ phase to the solid phase was detected but on heating an apparent very weak wide anomaly was visible beginning at about $0^{\circ} \mathrm{C}$ apart from the anomalies of the previously identified phase transitions.

To better illustrate the situation described, in Fig. 6 presentation is focused on the unusual anomaly by showing the enlarged fragment of DSC thermograms of Fig. 5. Now it is clear that during the first cycle $(10 \mathrm{~K} / \mathrm{min})$ up to melting the sample is only in the solid phase, we called crystal Cr1. In other cycles the exothermic nature of the anomaly observed on heating is the base of conclusion that the phase $\mathrm{SmI}^{*}$ obtained on cooling crystallizes to the metastable phase Cr2 transforming slowly to stable crystal Cr1. The enthalpy and entropy changes calculated for the phase transitions are collected in Table II. One can see that the thermal effects of anomalies between crystalline phases are much smaller than at clearing and crystallization/melting temperatures.

Figure 7 presents temperature of the phase transition vs. heating (a) and cooling (b) rate. Values of the phase transition temperatures depend on the rate of temperature changes in a similar way except of temperature of $\mathrm{SmI}^{*}-\mathrm{Cr} 2$ transition. Temperature of freezing point depends on the cooling rate much stronger, which is the general rule for most substances [7]. This process is the result of interplay of nucleation of crystalline seeds and the process of their growth which are characteristic fea-



Fig. 6. DSC thermogram fragment showing anomaly related to evolution of metastable crystal $\mathrm{Cr} 2$ to stable crystal $\mathrm{Cr} 1$ on heating with various rates. Dashed lines present the extension of the experimental line registered below minimum of anomaly towards higher temperatures for better visualization of anomalies. For experiment with heating rate of $10 \mathrm{~K} / \mathrm{min}$ sample is in the stable phase.

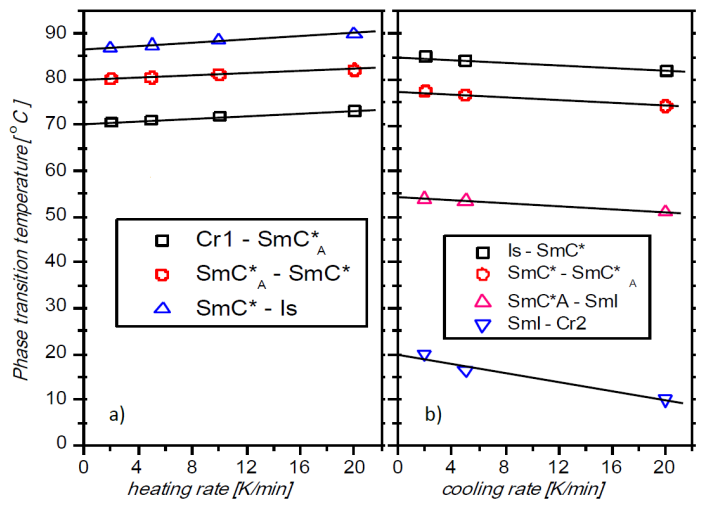

Fig. 7. Dependence of the phase transitions temperature $T_{P}$ vs. heating (a) and cooling (b) rate.

tures for each substance [8]. All dependences are linear, so they are fitted by linear functions of the form $T_{P}=a+b \Delta T / \Delta t$. Directional coefficient $b$ informs how the phase transition temperature $T_{P}$ changes with the rate of heating/cooling, while the value of $a$ is equal to the phase transition temperature at zero rate of heating/ cooling. Coefficients $a$ and $b$ are collected in Table III.

The DSC studies allow us to determine the following phase diagram of the substance at zero rate of heating and cooling of the sample:

$$
\begin{aligned}
& \text { Is }\left(85.2^{\circ} \mathrm{C}\right) \mathrm{SmC}^{*}\left(77.6^{\circ} \mathrm{C}\right) \mathrm{SmC}_{\mathrm{A}}^{*}\left(54.3^{\circ} \mathrm{C}\right) \\
& \quad \mathrm{SmI}^{*}\left(20.2^{\circ} \mathrm{C}\right) \mathrm{Cr} 2, \\
& \mathrm{Cr} 1\left(70.4^{\circ} \mathrm{C}\right) \mathrm{SmC}_{\mathrm{A}}^{*}\left(79.8^{\circ} \mathrm{C}\right) \mathrm{SmC}^{*}\left(86.6^{\circ} \mathrm{C}\right) \mathrm{Is} .
\end{aligned}
$$

Detailed observation of textures on cooling and heating the sample corroborate well with these results.

The next step was to check how the substance could be vitrified. For this purpose, the sample was cooled 
from $90^{\circ} \mathrm{C}$ to $-150^{\circ} \mathrm{C}$, with various cooling rates: 2,5 , and $10 \mathrm{~K} / \mathrm{min}$. In the first two cases no anomaly was observed at low temperatures. But on faster cooling with the rate of $10 \mathrm{~K} / \mathrm{min}$ an anomaly that might indicate a vitrification of glass of crystal $\mathrm{Cr} 2$ (GCr2) appears, as is shown in Fig. 8.

TABLE I

Phase transition temperature values obtained under different conditions of heating and cooling.

\begin{tabular}{|c|c|c|c|c|}
\hline $\begin{array}{c}\Delta T / \Delta t[\mathrm{~K} / \mathrm{min}] \\
\text { heating }\end{array}$ & Transition & Onset $\left[{ }^{\circ} \mathrm{C}\right]$ & Peak $\left[{ }^{\circ} \mathrm{C}\right]$ & End $\left[{ }^{\circ} \mathrm{C}\right]$ \\
\hline \multirow[t]{3}{*}{2} & $\mathrm{Cr} 1-\mathrm{SmC} \mathrm{A}_{\mathrm{A}}^{*}$ & 67.3 & 70.6 & 71.4 \\
\hline & $\mathrm{SmC}_{\mathrm{A}}^{*}-\mathrm{SmC}^{*}$ & 79.4 & 79.9 & 80.3 \\
\hline & $\mathrm{SmC}^{*}-\mathrm{Is}$ & 84.4 & 86.8 & 89.0 \\
\hline \multirow[t]{3}{*}{5} & $\mathrm{Cr} 1-\mathrm{SmC}_{\mathrm{A}}^{*}$ & 66.3 & 71.0 & 72.6 \\
\hline & $\mathrm{SmC}_{\mathrm{A}}^{*}-\mathrm{SmC}^{*}$ & 79.8 & 80.3 & 81.1 \\
\hline & $\mathrm{SmC}^{*}-\mathrm{Is}$ & 84.9 & 87.5 & 90.3 \\
\hline \multirow[t]{3}{*}{10} & $\mathrm{Cr} 1-\mathrm{SmC}_{\mathrm{A}}^{*}$ & 66.5 & 72.0 & 75.1 \\
\hline & $\mathrm{SmC}_{\mathrm{A}}^{*}-\mathrm{SmC}^{*}$ & 80.0 & 81.0 & 82.6 \\
\hline & $\mathrm{SmC}^{*}-\mathrm{Is}$ & 84.9 & 88.4 & 91.8 \\
\hline \multirow[t]{3}{*}{20} & $\mathrm{Cr} 1-\mathrm{SmC}_{\mathrm{A}}^{*}$ & 66.2 & 73.0 & 78.3 \\
\hline & $\mathrm{SmC}_{\mathrm{A}}^{*}-\mathrm{SmC}^{*}$ & 81.2 & 82.0 & 82.6 \\
\hline & $\mathrm{SmC}^{*}-\mathrm{Is}$ & 86.0 & 90.5 & \\
\hline $\begin{array}{c}\Delta T / \Delta t[\mathrm{~K} / \mathrm{min}] \\
\text { cooling }\end{array}$ & Transition & Onset $\left[{ }^{\circ} \mathrm{C}\right]$ & Peak $\left[{ }^{\circ} \mathrm{C}\right]$ & End $\left[{ }^{\circ} \mathrm{C}\right]$ \\
\hline \multirow[t]{4}{*}{2} & $\mathrm{Is}_{\mathrm{S}} \mathrm{SmC}^{*}$ & 87.1 & 85.0 & 84.3 \\
\hline & $\mathrm{SmC}^{*}-\mathrm{SmC}_{\mathrm{A}}^{*}$ & 77.7 & 77.4 & 77.0 \\
\hline & $\mathrm{SmC}_{\mathrm{A}}^{*}-\mathrm{SmI}^{*}$ & 58.6 & 53.9 & 48.2 \\
\hline & $\mathrm{SmI}-\mathrm{Cr} 2$ & 22.6 & 20.1 & 18.5 \\
\hline \multirow[t]{4}{*}{5} & Is-SmC & 86.2 & 84.3 & 82.0 \\
\hline & $\mathrm{SmC}^{*}-\mathrm{SmC}_{\mathrm{A}}^{*}$ & 77.1 & 76.7 & 75.8 \\
\hline & $\mathrm{SmC}_{\mathrm{A}}^{*}-\mathrm{SmI}^{*}$ & 58.3 & 53.4 & 47.6 \\
\hline & $\mathrm{SmI}^{*}-\mathrm{Cr} 2$ & 19.1 & 16.5 & 14.1 \\
\hline \multirow[t]{4}{*}{20} & Is-SmC ${ }^{*}$ & 84.8 & 81.5 & 77.3 \\
\hline & $\mathrm{SmC}^{*}-\mathrm{SmC}_{\mathrm{A}}^{*}$ & & 74.2 & \\
\hline & $\mathrm{SmC}_{\mathrm{A}}^{*}-\mathrm{SmI}^{*}$ & 56.9 & 51.4 & 43.3 \\
\hline & $\mathrm{SmI}^{*}-\mathrm{Cr} 2$ & 13.1 & 9.6 & 5.0 \\
\hline
\end{tabular}

TABLE II

Enthalpy and entropy changes values at phase transitions observed during heating and cooling.

\begin{tabular}{c|c|c|c|c|c|c}
\hline \hline \multirow{2}{*}{ Process } & Phase transition & $\begin{array}{c}T_{P} \\
{\left[{ }^{\circ} \mathrm{C}\right]}\end{array}$ & $\begin{array}{c}\Delta H \\
{[\mathrm{~J} / \mathrm{g}]}\end{array}$ & $\begin{array}{c}\Delta H \\
{[\mathrm{~kJ} / \mathrm{mol}]}\end{array}$ & $\begin{array}{c}\Delta S \\
{[\mathrm{~mJ} /(\mathrm{K} \mathrm{g})]}\end{array}$ & $\begin{array}{c}\Delta S \\
{[\mathrm{~J} /(\mathrm{K} \mathrm{mol})]}\end{array}$ \\
\hline \multirow{2}{*}{ endothermic } & $\mathrm{Cr} 1-\mathrm{SmC}_{\mathrm{A}}^{*}$ & 70.4 & -37 & -25.5 & -107 & -73.9 \\
& $\mathrm{SmC}_{\mathrm{A}}^{*}-\mathrm{SmC}^{*}-$ & 79.8 & -0.09 & -0.06 & -0.25 & -0.17 \\
& $\mathrm{SmC}^{*}-\mathrm{Is}$ & 86.6 & -18 & -12.4 & -50 & -34.5 \\
\hline \multirow{2}{*}{ exothermic } & $\mathrm{Is}^{-} \mathrm{SmC}^{*}$ & 85.2 & 13 & 8.9 & 36 & 24.9 \\
& $\mathrm{SmC}^{*}-\mathrm{SmC}_{\mathrm{A}}^{*}$ & 77.6 & 0.10 & 0.07 & 0.28 & 0.19 \\
& $\mathrm{SmC}_{\mathrm{A}}^{*}-\mathrm{SmI}^{*}$ & 54.3 & 2.3 & 1.59 & 7.1 & 4.9 \\
& $\mathrm{SmI}^{*}-\mathrm{Cr} 2$ & 20.2 & 15 & 10.4 & 51 & 35.2 \\
& & & & &
\end{tabular}

The value of the glass transition temperature $T_{\mathrm{g}}=-115^{\circ} \mathrm{C}$ was estimated. On the basis of the results obtained on cooling and heating with the rate of $10 \mathrm{~K} / \mathrm{min}$ the following sequence of phases is proposed for 1-[3-fluoro-4-(1-methylheptyloxycarbonyl)phenyl]-2- -[4'-(2,2,3,3,4,4,4-heptafluorobutoxybutoxy)biphenyl-4yl]ethane

$$
\begin{gathered}
\text { Is }\left(83^{\circ} \mathrm{C}\right) \mathrm{SmC}^{*}\left(76^{\circ} \mathrm{C}\right) \mathrm{SmC}_{\mathrm{A}}^{*}\left(53^{\circ} \mathrm{C}\right) \\
\mathrm{SmI}^{*}\left(13^{\circ} \mathrm{C}\right) \mathrm{Cr} 2\left(-115^{\circ} \mathrm{C}\right) \mathrm{GCr} 2,
\end{gathered}
$$


GCr2 (nonvisible) $\mathrm{Cr} 2\left(5^{\circ} \mathrm{C}\right) \mathrm{Cr} 1\left(72{ }^{\circ} \mathrm{C}\right)$

$\mathrm{SmC}_{\mathrm{A}}^{*}\left(81^{\circ} \mathrm{C}\right) \mathrm{SmC}^{*}\left(88^{\circ} \mathrm{C}\right)$ Is.

TABLE III

Coefficients $a$ and $b$ in the $T_{P}=a+b \Delta T / \Delta t$ equation describing $T_{P}$ vs. $\Delta T / \Delta t$ on heating/cooling.

\begin{tabular}{c|c|c}
\hline \hline Phase transition & $a\left[{ }^{\circ} \mathrm{C}\right]$ & $b[\mathrm{~min}]$ \\
\hline \multicolumn{3}{|c}{ Heating } \\
\hline $\mathrm{Cr}-\mathrm{SmC}_{\mathrm{A}}^{*}$ & $70.41 \pm 0.17$ & $0.135 \pm 0.015$ \\
$\mathrm{SmC}_{\mathrm{A}}^{*}-\mathrm{SmC}^{*}$ & $79.79 \pm 0.06$ & $0.112 \pm 0.006$ \\
$\mathrm{SmC}^{*}-\mathrm{Is}$ & $86.58 \pm 0.14$ & $0.175 \pm 0.012$ \\
\hline \multicolumn{3}{c}{ Cooling } \\
\hline $\mathrm{IS}^{\mathrm{S}} \mathrm{SmC}^{*}$ & $85.20 \pm 0.17$ & $-0.161 \pm 0.014$ \\
$\mathrm{SmC}^{*}-\mathrm{SmC} \mathrm{A}$ & $77.61 \pm 0.18$ & $-0.172 \pm 0.015$ \\
$\mathrm{SmC}_{\mathrm{A}}^{*}-\mathrm{SmI}$ & $54.27 \pm 0.06$ & $-0.163 \pm 0.005$ \\
$\mathrm{SmI}^{*}-\mathrm{Cr} 2$ & $20.21 \pm 1.28$ & $-0.520 \pm 0.107$
\end{tabular}

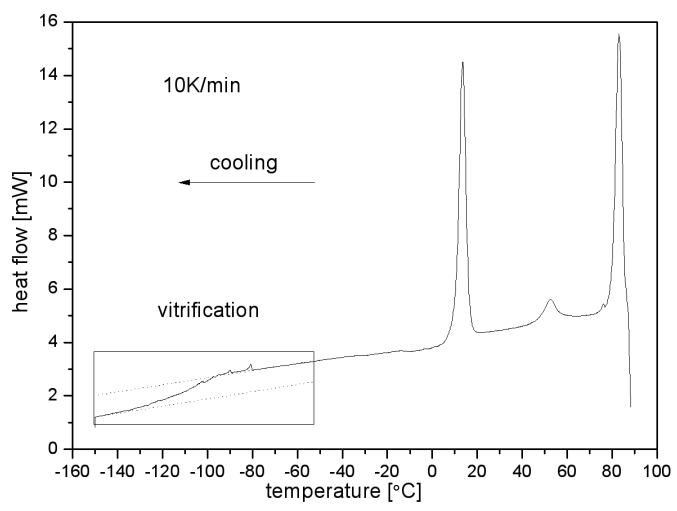

Fig. 8. DSC thermogram obtained on cooling with the rate of $10 \mathrm{~K} / \mathrm{min}$.

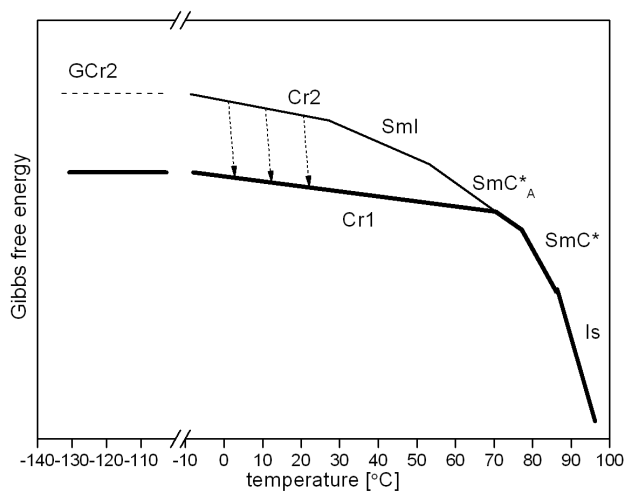

Fig. 9. Schematic Gibbs free energy for 1-[3fluoro-4-(1-methylheptyloxycarbonyl)phenyl]-2-[4'-(2,2,3,3,4,4,4-heptafluorobutoxybutoxy)biphenyl-4yl]ethane. Stable phases are marked by bold lines, metastable phases by solid lines and glass of $\mathrm{Cr} 2$ by dashed line. Arrows mean $\mathrm{Cr} 2-\mathrm{Cr} 1$ evolution.

The Gibbs free energy diagram showing the monotropic system of phases is schematically drawn in Fig. 9. Dynamics in glassforming crystal Cr2 was recently evidenced using dielectric spectroscopy [9]. A weak complex relaxation connected with conformational rotations, which are probably stopped below $T_{\mathrm{g}}$, was found. Conformational freedom in glassforming crystal phase was reported for some liquid crystalline materials of smaller molecules $[10,11]$.

\section{Conclusions}

For 1-[3-fluoro-4-(1-methylheptyloxycarbonyl)phenyl]-2-[4'-(2,2,3,3,4,4,4-heptafluorobutoxybutoxy)biphenyl-4-yl]ethane two enantiotropic liquid crystalline phases, ferroelectric $\mathrm{SmC}^{*}$ and antiferroelectric $\mathrm{SmC}_{\mathrm{A}}^{*}$, and one monotropic liquid crystalline SmI phase have been observed. On cooling SmI* phase crystallizes to metastable crystal $\mathrm{Cr} 2$ which on heating evolves slowly to stable crystal Cr1 melting to $\mathrm{SmC}_{\mathrm{A}}^{*}$. The sequence of phases was observed using three methods, i.e. light transmission intensity, differential scaning calorimetry and polarizing microscope observations. In DSC during rapid cooling of the substance $(10 \mathrm{~K} / \mathrm{min})$, vitrification of the crystal $\mathrm{Cr} 2$ phase was registered at $T_{\mathrm{g}}=-115^{\circ} \mathrm{C}$.

\section{References}

[1] W.H. de Jeu, Physical Properties of Liquid Crystalline Materials, Gordon and Breach, New York 1980.

[2] R.B. Meyer, L. Liebert, L. Strzelecki, P. Keller, J. Phys. Lett. 36, L69 (1975).

[3] A.P.L. Chandani, E. Górecka, Y. Ouchi, H. Takezoe, A. Fukuda, Jpn. J. Appl. Phys. 28, L1265 (1989).

[4] S.T. Lagerwall, Ferroelectric and Antiferroelectric Liquid Crystals, Willey-VCH, Weinheim 1999.

[5] P. Kula, A. Spadło, M. Żurowska, R. Dąbrowski, Synletters 9, 1394 (2010).

[6] S. Wróbel, A. Fąara, M. Marzec, W. Haase, R. Dąbrowski, W. Drzewiński, B. Gestblom, M. Makrenek, Phase Transit. 80, 791 (2007).

[7] E. Juszyńska, M. Massalska-Arodź, P.M. Zieliński, Phase Transit. 79, 899 (2006).

[8] J. Ściesiński, E. Ściesińska, M. Massalska-Arodź, T. Wasiutyński, P.M. Zieliński, W. Witko, IEEE Trans. Diel. Electr. Insulat. 8, 522 (2001).

[9] Ł. Kolek, M. Massalska-Arodź, M. Paluch, K. Adrjanowicz, T. Rozwadowski, D. Majda, in preparation.

[10] A. Inaba, M. Massalska-Arodź, H. Suzuki, J. Krawczyk, Mol. Cryst. Liq. Cryst. 540, 102 (2011).

[11] M. Massalska-Arodź, E. Ściesińska, J. Ściesiński, J. Krawczyk, A. Inaba, P.M. Zieliński, in: Dielectric Properties of Liquid Crystals, Eds. Z. Galewski, L. Sobczyk, Transworld Research Network, Kerala 2007, p. 159 . 